\title{
HABILIDADES SOCIAIS NO MERCADO DE LEITE
}

\section{RESUMO}

O crescimento de cooperativas de agricultores familiares na região Sul do Brasil contradiz a maioria dos estudos de mercado, que prevêem um processo inexorável de globalização, concentração de mercado e exclusão dos produtores mais pobres. O objetivo deste artigo é discutir como as cooperativas conseguiram garantir a estabilidade da oferta de leite em um ambiente competitivo, mesmo dispondo de poucos recursos econômicos. O artigo aponta que as habilidades sociais das cooperativas foram decisivas na definição de sua posição de destaque nesse mercado. Essas habilidades expressam-se na capacidade de mobilizar capital social e simbólico, de formar uma nova identidade social em torno da produção familiar de leite, de estimular a cooperação e manter estáveis as relações com os seus fornecedores. A conclusão deste trabalho aponta que só uma abordagem territorial desses mercados pode nos ajudar a compreender por que são formadas variadas organizações de produtores e por que fatores não econômicos são determinantes para a concorrência.

\section{Reginaldo Sales Magalhães}

Procam - USP

\begin{abstract}
In Southern Brazil the family farmer cooperative growth shows the deficiency of the majority of market studies. These studies foresee an inexorable globalization process, market concentration and exclusion of the poorest producers. The objective of this article is to understand how stable milk offering for the cooperative is guaranteed in a competitive environment, even with few economic resources. The sociological market study shows that important position in the market was occupied because of the social skills of the cooperative. These skills are expressed by the capacities to mobilize social and symbolic capital, to form a new social identity, to stimulate the cooperation and to maintain stable relations with suppliers. Conclusions point out that only a territorial approach of the markets can understand why varied organizations of producers are formed and why not economic factors are determinant for the competition.
\end{abstract}

PALAVRAS-CHAVE Mercados, territórios, cooperativas, habilidades sociais, sociologia econômica. KEYWORDS Markets, territories, cooperatives, social skills, economic sociology. 


\section{INTRODUÇÃO}

Desmentindo todas as previsões feitas nas últimas décadas, segundo as quais o mercado lácteo tenderia a concentrar a captação de leite em grandes empresas multinacionais do setor, três novos sistemas de cooperativas de agricultores familiares vêm ampliando sua posição no mercado da região Sul do Brasil. Erros nas previsões dos especialistas ou capacidade excepcional das novas cooperativas? Na verdade, o que parece justificar a aparente contradição entre prognósticos e fatos são as insuficiências teóricas que sustentam os estudos sobre os mercados e as organizações.

A maioria das análises do mercado de leite enfatiza fortemente o processo de concentração da indústria e as mudanças de um padrão de produção e mercado que até há poucos anos estava restrito ao âmbito local e que passa a ter dinâmicas cada vez mais globais. A difusão de novas tecnologias, que levou ao aumento do consumo de leite com embalagens de longa vida e de leite em pó, tornou possível a conservação do produto por períodos mais longos e o transporte por extensas distâncias, transformando-se assim o leite numa commodity. Segundo Carvalho (2005, p. 15), a dinâmica setorial passa a ser dada exogenamente, pelas matrizes estrangeiras ou pelos demandantes do produto.

Partindo dessas premissas, os estudos que analisam as condições de mercado em territórios específicos analisam apenas o impacto de mudanças globais ou macroeconômicas sobre as condições locais de produção. Estariam então os territórios e seus agentes totalmente subordinados a uma lógica global? Estariam as regras de mercado e os padrões de produção subordinados às determinações estabelecidas pelas grandes empresas líderes mundiais? É o que parecia se confirmar ao longo dos anos 1990. A Parmalat se instalou na região com intensa agressividade, comprando pequenas indústrias e ameaçando formar um monopólio na indústria de leite e laticínios na região Sul. Com o aumento da competição nos mercados de leite, as cooperativas tradicionais passaram a adotar uma série de medidas visando a reduzir custos, principalmente por meio da profissionalização da gestão, da seleção e da redução do quadro de cooperados (Jank e Galan, 1997).

Alguém que observasse com pouca atenção essas intenções poderia emitir o juízo de que o destino da região estava selado. Porém, não foi o que ocorreu: a formação e a expansão das novas cooperativas de agricultores familiares contradizem tais previsões para o mercado de leite brasileiro. Por quê?

Em primeiro lugar, porque, ao lado de grandes empresas multinacionais e laticínios de médio porte, está se consolidando um modelo de organização produtiva baseado em redes de pequenas cooperativas. Tais organizações foram formadas a partir da iniciativa de organizações sociais que, diferentemente do modelo tradicional, conseguem alcançar níveis razoáveis de competitividade justamente com os agricultores excluídos. Como conseqüência, em vez da tão propalada exclusão social, a organização econômica redundou, por meio da intervenção dos atores sociais, em uma atenuação do processo de concentração da renda.

Essa não é, todavia, a visão predominante sobre os mercados: a maioria dos estudos se concentra na análise da concorrência entre as empresas pelo mercado consumidor, mas não aborda o problema da concorrência pelo acesso à matéria-prima. Segundo Fligstein (2001), os mercados são mais bem caracterizados pela relação entre produtores concorrentes de um mesmo segmento - e não pela relação entre produtores e consumidores. Para White (1981), os comportamentos dos agentes econômicos não são orientados por uma demanda amorfa: em vez disso, os produtores se observam uns aos outros dentro de uma estrutura social em que as ações consideradas mais eficientes são reproduzidas.

As empresas buscam mais do que a maximização de curto prazo dos seus lucros. Querem sobreviver por meio do estabelecimento de relações estáveis com fornecedores e competidores. Para os estudos que se restringem aos pressupostos da economia neoclássica, as firmas são caixas-pretas, impenetráveis ao olhar de um cientista que não leve em consideração as estruturas, as relações sociais e a história que as construíram. Outra limitação teórica importante dos estudos sobre os mercados é que costumam restringir-se ao campo econômico. Entretanto, a formação dos mercados e suas constantes mudanças, bem como os comportamentos econômicos dos indivíduos, são resultado de interações freqüentes entre campos econômicos, políticos e culturais (Bourdieu, 2005). Sem levar em conta as influências do mundo social, importantes fenômenos econômicos são negligenciados pelos estudos de mercado baseados nas teorias econômicas neoclássicas.

$\mathrm{Na}$ verdade, vemos que os mercados são resultados de configurações de interesses econômicos e relações sociais (Swedberg, 2003) que se estabelecem de diferentes formas, dependendo da estrutura e da posição que cada agente ocupa no campo de forças. Cada agente constrói estratégias de luta e de cooperação. Alianças entre empresas, cooperativas, sindicatos e produtores são estratégias encontradas pelos agentes econômicos para estabilizar as relações entre competidores. São coalizões de interesses e compromissos, muitas vezes na esfera dos domínios 
políticos, que permitem a estabilização dos mercados (Fligstein, 2001).

Se existem então condições específicas em que os mercados apresentam características particulares para um dado território, poderíamos conceber a existência de mercados territoriais? Mercados são arenas sociais onde ocorrem trocas estruturadas, que por sua vez necessitam de regras e estruturas sociais para guiar e organizar as transações. A formação de um mercado territorial se consolida na medida em que as organizações, neste caso as cooperativas, formem instituições peculiares no território em questão.

Os mercados de leite se caracterizam por interações complexas entre diversos agentes. Para que essas interações se estabilizem, é necessário que os atores compartilhem pressupostos cognitivos, padrões habituais e regras para governar novas interações. Ou seja, para que se formem mercados com características específicas em um território, é necessário que existam nele determinadas estruturas sociais. De acordo com Fligstein (2001), essas estruturas podem ser classificadas em quatro categorias, a saber: direitos de propriedade, estruturas de governança, regras de troca e concepções de controle.

A primeira categoria, direitos de propriedade, define as relações sociais entre os proprietários e o conjunto da sociedade, produzindo dois tipos de estabilidade: definem o poder nas relações intra e interfirmas. A segunda categoria, estruturas de governança, refere-se às regras gerais, tanto formais quanto informais, de uma sociedade, que estabelecem relações de cooperação e competição e limitam o modo de organização dessas sociedades. A terceira categoria, concepções de controle, reflete arranjos específicos de mercado entre atores em firmas segundo princípios de organização interna, táticas de cooperação e competição, e hierarquias ou o ordenamento das firmas em um dado mercado. A concepção de controle é uma forma de "conhecimento local" (Geertz, 1983). É um produto historicamente específico a cada indústria, a cada sociedade e cultura, na medida em que forma um tipo de compreensão e práticas disponíveis em um dado mercado. Por fim, a quarta categoria, regras de troca, define quem pode transacionar com quem, e as condições em que essas transações são realizadas, sendo que a padronização de produtos é cada vez mais importante nesse contexto. As mudanças nos mercados de leite promovidas pelas cooperativas são analisadas sob o ângulo dessas estruturas sociais.

Uma série de fatores faz com que haja uma grande concorrência no mercado de leite na região Sul do Brasil. As empresas se engajam em uma dura guerra de preços para garantir o acesso à matéria-prima. As novas cooperativas, mediante a organização de um grande número de produtores, conseguiram elevar os preços recebidos, porém com freqüência as empresas utilizam a mesma estratégia para conquistar novos produtores. O principal objetivo dessa pesquisa foi compreender como as cooperativas conseguiram garantir a estabilidade da oferta de leite em um ambiente tão competitivo e dispondo de pouquíssimos recursos econômicos. Uma questão que se apresenta como um grande desafio para a ciência econômica e para os tradicionais estudos de mercado é: por que os produtores de leite se mantêm fieis às cooperativas, mesmo quando recebem propostas de preços melhores por parte das empresas concorrentes?

Essa questão será analisada à luz da sociologia econômica e confrontada com evidências empíricas levantadas junto a três sistemas de cooperativas de produtores de leite localizadas nas regiões sudoeste do Paraná, oeste de Santa Catarina e noroeste do Rio Grande do Sul. Por meio de entrevistas com dirigentes e técnicos de cooperativas, produtores e lideranças de organizações sociais, identificaram-se as relações sociais, as formas de organização e as instituições que estruturam o mercado de leite nessas regiões. Além disso, foram reconstruídos processos históricos que levaram à mudança nas relações entre os produtores e as indústrias, e à formação das cooperativas. Nas próximas sessões, são analisadas as características do mercado de leite na região, as formas de organização das cooperativas e as relações sociais entre organizações e agricultores familiares. Ao final, são apresentadas as conclusões a respeito do papel que as habilidades sociais dos agricultores familiares e suas cooperativas cumpriram na conquista de maiores espaços no mercado de leite da região.

\section{O MERCADO REGIONAL DE LEITE}

O tradicional mercado de leite caracterizava-se por um comércio local, em geral pouco regulamentado por regras formais, com predomínio de pequenos produtores e laticínios artesanais, em uma cadeia de produção curta, com poucos intermediários entre os produtores primários e os consumidores, e baixo valor agregado aos produtos. Era a época do leiteiro, que deixava o leite à frente da porta do consumidor. Desde então, a intervenção estatal passou a ter influência constante no mercado de leite. De 1945 a 1991, o principal instrumento de regulação do mercado foi o tabelamento de preços, que, junto com os programas sociais de distribuição de leite, por meio das compras institucionais, fizeram com que os governos passassem a ser os principais demandantes do produto. Segundo Carvalho 
(2005, p. 3), no final dos anos 1990, os programas sociais consumiam aproximadamente $30 \%$ do total do leite tipo C produzido no Brasil. Nesse período, o governo adotou mecanismos indiretos de orientação da produção, mediante políticas de crédito, pesquisa e assistência técnica.

A ação do Estado no mercado de leite foi alvo de muitas críticas. O tabelamento foi apontado como principal fator responsável pela baixa produtividade e qualidade dos produtos lácteos, com a existência de indústrias com grande capacidade ociosa e sérios problemas de gestão e de eficiência. A crise crescente do setor ampliou a dependência de importação, que, junto com o fim do tabelamento, levou a uma grande mudança institucional no setor e à formação de novos arranjos produtivos.

Segundo Pilati (2004, p. 12), por serem produtos perecíveis e de giro rápido, os lácteos se caracterizam por compras repetitivas. Porém, são muito sensíveis às oscilações de preço, qualidade, atendimento e serviços de logísticas dos ofertantes. Muitas vezes, a mudança de 1 centavo no preço de 1 litro de leite, por exemplo, pode influenciar na decisão de indústrias, atacadistas e supermercados. Ou seja, o mercado de leite é caracterizado por uma forte concorrência, tanto no acesso à matéria-prima quanto na oferta para o mercado consumidor. Apesar da crescente concentração da industrialização de leite em grandes empresas de atuação global, o mercado de leite apresenta pesada concorrência nas duas pontas da cadeia. É, em suma, um mercado com grande instabilidade, provocada pelas constantes oscilações na oferta nas regiões produtoras, além de muito sensível às oscilações econômicas, aos subsídios governamentais, à política cambial e às variações climáticas.

Apesar do ambiente instável, na última década a produção brasileira de leite cresceu 48\%; o consumo interno cresceu $42 \%$, ao passo que as importações reduziram-se em $82 \%$ e as exportações cresceram $666 \%$ - o que levou, em 2004, a uma balança comercial positiva. Por outro lado, desde 1973 o preço de leite vem apresentando queda constante (Neves et alii, 2005).

A maioria das pesquisas indica que há um crescente processo de globalização nos mercados de leite, baseado em algumas grandes mudanças. Primeira, a abertura comercial do início dos anos 1990, que elevou os padrões de competitividade, obrigando as empresas a adotar novas estratégias, reduzir custos, aumentar a escala de produção e melhorar a qualidade do produto. Segunda, a adoção da tecnologia de esterilização do leite e da embalagem longa vida, que transformou o leite em uma commodity, permitindo a comercialização a longas distâncias e o armazenamento do produto por prazos longos. Terceira, o aumento de fusões e aquisições, principais estratégias utilizadas no final dos anos 1990 e início dos anos 2000. Entre 1989 e 1999, por exemplo, a Parmalat adquiriu 22 plantas industriais e a Nestlé, outras 8 plantas. Esses casos foram considerados uma tendência para o setor (Carvalho, 2005, p. 5).

Em quarto lugar, a regulamentação da qualidade do leite está provocando uma grande reestruturação nos sistemas produtivos e na relação entre as indústrias e os produtores, principalmente com a entrada em vigor da portaria 56 do Ministério da Agricultura, a qual estabelece novos padrões técnicos, higiênicos e sanitários para a produção de leite. Adicionalmente, os elevados investimentos no setor deverão, segundo as previsões, causar uma grande exclusão de produtores que não tenham condições de ter acesso aos recursos necessários para manter a atividade.

Uma das principais limitações dessas análises é sua tendência de sobrepor a importância de fatores exógenos e não levar em conta as estratégias utilizadas pelas empresas e organizações para ocupar melhores posições no mercado. Se fossem consideradas as relações endógenas entre as indústrias e os produtores de leite, seriam observadas situações específicas nas quais os mercados de leite, em importantes regiões, mantêm características locais, determinadas por instituições próprias de cada território. $\mathrm{O}$ conhecimento concreto revela que o preço não está dado, nem é o resultado abstrato do equilíbrio entre oferta e demanda, mas é objeto de constantes tentativas de manipulação pelo uso do poder que cada agente dispõe. Todos os mercados são regulados por estruturas sociais. Garcia-Parpet (2003, p. 25-29), por exemplo, mostra que a dinâmica de um mercado é permanentemente influenciada por agentes que se reorganizam, criam laços, fazem acordos, formam redes de comunicação, reduzem a transparência e reforçam vínculos com o objetivo de eliminar a concorrência. Assim, preservar a concorrência depende de um contínuo esforço de controle.

A Mesorregião Grande Fronteira Mercosul, um grande território que engloba o sudoeste do Paraná, o oeste de Santa Catarina e o noroeste do Rio Grande do Sul, ocupa o segundo lugar na produção de leite do país, perdendo apenas para o estado de Minas Gerais. A região tem uma produção de leite maior, por exemplo, que toda a produção do Uruguai. O leite é especialmente importante na reprodução da agricultura familiar, atingindo quase a totalidade dos estabelecimentos agrícolas do território.

Na região, a produção tomou vulto a partir de meados dos anos 1980 e final dos anos 1990, quando a indústria de suínos e aves promoveu uma grande concentração da 
produção, excluindo um grande número de produtores familiares. Com maior densidade de ocupação de mãode-obra, possibilidade de descentralização de parte da indústria em pequenas unidades e menor valor dos investimentos necessários, a produção de leite foi a melhor alternativa encontrada (Testa et alii, 2003, p. 15). Ao contrário da suinocultura e da avicultura, que apresentam um mercado muito concentrado em grandes indústrias (Sadia, Chapecó, Perdigão, etc.), o mercado de leite apresenta uma estrutura menos concentrada e com maior concorrência. Muitos produtores de soja, pressionados pelas grandes oscilações de preços e pelas perdas recentes provocadas por variações climáticas, vêm também convertendo suas unidades de produção para a bovinocultura de leite.

Com oferta e demanda crescentes, grande número de empresas disputa o acesso aos produtores. No oeste de Santa Catarina, 51 empresas, sendo 14 cooperativas, 2 laticínios médios, 17 laticínios pequenos, 2 multinacionais e 16 miniusinas, concorrem pelo leite vendido por $40 \mathrm{mil}$ produtores, em 118 municípios (Testa et alii, 2003, p. 29). Com tal grau de concorrência, as principais empresas não conseguem definir padrões de preço e qualidade, abrindo espaço para novos agentes serem formados e ampliarem posições no mercado. As grandes cooperativas tradicionais perderam espaço, que foram ocupados principalmente por laticínios regionais. Um grande número de pequenos laticínios ainda se mantém na atividade, sustentando-se por meio dos mercados informais.

Mesmo nesse ambiente de grande concorrência, três sistemas de cooperativas da agricultura familiar construíram, em poucos anos, uma participação expressiva no mercado da região. A questão que nos fazemos neste ponto é se a forma de organização desses sistemas ajuda a explicar seu desempenho. É o que veremos a seguir.

\section{A ORGANIZAÇÃO DAS COOPERATIVAS}

O sistema Coorlac, criado em 1994, surgiu do processo de privatização da antiga Corlac, Companhia Riograndense de Laticínios e Correlatos, em um processo de negociação conduzido pelos sindicatos de trabalhadores. A empresa enfrentava crise e sucateamento há alguns anos, resultado de grande endividamento junto a produtores, funcionários e tributos. Após longa negociação entre governo do estado produtores e sindicatos, definiu-se um processo de cooperativização. Os postos de recolhimento e indústrias da antiga Corlac foram desmembrados e passaram a ser administrados por cooperativas. Atualmente esse sistema é formado por uma central estadual, pela Coorlac, quatro centrais regionais e 22 cooperativas singulares. Destas, 21 são formadas por agricultores familiares e uma é formada por ex-funcionários da estatal. A Coorlac ocupava, segundo dados de 2002 da Associação Brasileira dos Produtores de Leite, a décima sétima posição no ranking nacional de empresas em volume de produção, com média de $20 \mathrm{mi}$ lhões de litros por mês, e o sétimo lugar com relação ao número de produtores, com 6 mil associados.

Em Santa Catarina, as cooperativas de leite da agricultura familiar começaram a ser formadas a partir de 2001, pela iniciativa de 26 famílias no município de Arvoredo, com o apoio dos sindicatos da agricultura familiar de Chapecó e Coronel Freitas. Dessa primeira organização foram criadas outras 7 cooperativas que integram a Associação das Cooperativas Produtoras de Leite do Oeste Catarinense (Ascooper). O sistema de cooperativas tem 2.200 sócios que produzem cerca de 3 milhões de litros de leite por mês. A Ascooper tem o apoio de um conjunto de parceiros. Os principais são a Apaco (Associação dos Pequenos Agricultores do Oeste Catarinense), que faz assessoria na gestão da cooperativa e dos produtores de leite, os sindicatos da agricultura familiar, que auxiliam no trabalho de organização dos produtores, e o Sistema Cresol, que oferece crédito para os produtores e cooperativas.

As cooperativas possuem uma organização descentralizada cuja principal função é manter uma relação contínua e estreita com os associados. Cada cooperativa possui uma coordenação formada por representantes dos municípios que fazem parte de sua área de abrangência. Em cada município existe uma coordenação local, e, em cada comunidade, duas ou três lideranças são responsáveis pela relação com os associados. As lideranças comunitárias reúnem-se regularmente com os sócios em cada comunidade para discutir preços, produção e transporte. Esse formato organizacional permite uma relação de proximidade com os associados que resulta em grande participação. As cooperativas não possuem uma estrutura de comercialização e industrialização. Elas atuam exclusivamente no processo de organização dos produtores, e o seu papel é negociar o volume total de produção com as empresas que industrializam leite na região, uma vez que as indústrias não possuem uma estrutura similar de coordenação local para garantir o abastecimento do produto.

No Paraná, o Sistema de Cooperativas de Leite da Agricultura Familiar com Interação Solidária (Sisclaf) é composto por 16 cooperativas singulares e por uma cooperativa central. As primeiras cooperativas do sistema foram formadas em 1998, e a cooperativa central foi criada em 2004. As cooperativas singulares têm abrangência municipal com o papel de organizar grupos de 
produtores, coordenar a assistência técnica local, e são organizadas por meio de pequenos grupos comunitários. A direção da cooperativa reúne todos os coordenadores de grupos para discutir as condições do mercado, da produção, do transporte, a assistência técnica e as estratégias da cooperativa.

As cooperativas locais se integram em núcleos regionais cujos objetivos são promover a articulação das cooperativas em microrregiões, fazer a negociação com parceiros regionais, coordenar a assistência técnica, controlar a coleta e a qualidade do leite. A cooperativa central tem o papel de formular estratégias e projetos para o sistema, prestar serviços de apoio às cooperativas e representar o conjunto das organizações. O sistema possui 2 mil associados que produzem, em média, cerca de 2,5 milhões de litros de leite por mês. Para administrar esse complexo sistema de logística cada cooperativa possui apenas um pequeno escritório, com um funcionário e um ou dois dirigentes parcialmente liberados para o trabalho de organização, cadastramento, negociação com empresas, pagamento aos cooperados e venda de insumos e equipamentos.

Os três sistemas de cooperativas de leite reúnem-se no Fórum Sul do Leite, uma organização criada em 2003 com o apoio do Sistema Cresol, da Federação dos Trabalhadores da Agricultura Familiar da Região Sul (Fetraf-Sul) e de ONGs. O papel dessa organização é representar os três sistemas na negociação de políticas públicas relacionadas à cadeia de produção de leite, promover intercâmbios entre os sistemas e a negociação de projetos de capacitação e assistência técnica, e sua principal função é ampliar o acesso a recursos públicos.

A análise do papel das organizações na estruturação dos mercados é um tema central para a Economia Institucional. Segundo a economia dos custos de transação (Williamson, 1989), são os altos custos de contratação, monitoramento e enforcement que as empresas têm que assumir para se relacionar com grande número de pequenos produtores que explicam a opção preferencial por poucos produtores de grande escala. O acesso dos agricultores familiares aos mercados de leite por meio da venda de matéria-prima para grandes laticínios só seria possível com sistemas de governança que viessem a possibilitar uma redução dos custos de transação.

No entanto, mais do que reduzir os custos de transação, as cooperativas de leite conseguiram desenvolver e mobilizar, de forma eficiente, importantes recursos que propiciaram a sua expansão no mercado. Em primeiro lugar, elas criaram um tipo de capital tecnológico (Bourdieu, 2005 , p. 25), originalmente desenvolvido nas cooperativas de crédito e utilizado nas cooperativas de leite. A capacidade de criar essa complexa organização depende de uma série de procedimentos e competências únicas, que Geerz (1983) define como conhecimento local, construído por uma longa história de relacionamento entre as organizações e os agricultores familiares. Em segundo lugar, as cooperativas conseguiram transformar em capital econômico um grande capital simbólico baseado em uma forte identidade dos agricultores familiares que estimula a confiança, a credibilidade e o reconhecimento da organização. É a essa capacidade de mobilizar diferentes formas de capital como estratégia de alçar agricultores familiares pobres a posições de maior destaque no mercado de leite que chamamos habilidades sociais das cooperativas.

\section{HABILIDADES SOCIAIS}

As teorias baseadas na Economia Institucional analisam a condição de as empresas ampliarem a participação nos mercados em função da capacidade que possuam para adotar estruturas organizacionais, sobretudo estratégias financeiras, estratégias de formação de preço e controle de propriedade, adequadas às condições de mercado (Karlson, 2005). Além dos aspectos econômicos, o acesso dos agricultores familiares na cadeia do leite dependeria ainda de uma "coordenação eficiente" facilitada por governos que contribuíssem para a redução dos riscos e dos custos de governança, facilitando o fluxo de informações, o acesso a crédito, seguro e organizações de P\&D (Zylbersztajn, 1995).

As cooperativas, em particular, apresentam problemas específicos nas estruturas de controle de propriedade. Segundo Bialoskorski (1999), como nas cooperativas os direitos de propriedade são difusos, problemas de governança como assimetrias de informação entre diretoria $e$ associados, problemas de agência e custos de participação são mais freqüentes. Partindo dessa abordagem analítica, as recomendações para controlar a emergência de comportamentos oportunistas acaba por centrar-se nas estratégias de gestão das cooperativas que visem ao fortalecimento das estruturas de representação, na transparência de informação, na redução dos custos de transação, na coordenação contratual, no aumento da participação dos cooperados e na redução dos conflitos de agência (Bialoskorski, 2002).

O ambiente de grande incerteza que caracteriza o mercado de leite exige a definição de regras que regulem o relacionamento entre as organizações, e entre as organizações e os indivíduos. As três cooperativas de leite analisadas neste artigo formaram um ambiente institucional 
(North, 1990) que possibilita uma interação estável e previsível que permite tanto às cooperativas quanto aos produtores menos capitalizados manterem sua inserção no mercado.

Essa poderia ser uma boa explicação para a fidelidade que os agricultores familiares buscam preservar nas suas relações com as cooperativas em detrimento das melhores ofertas dos grandes laticínios. Parte dos problemas enfrentados pelas organizações e das estratégias por elas construídas pode ser compreendida à luz da Economia Institucional, porém essa abordagem se limita à análise dos problemas e estratégias oriundos das relações entre indivíduos e organizações. Uma visão subsocializada do comportamento dos atores, como definiu Granovetter (1985), não permite compreender como as relações sociais se entrelaçam com a vida econômica e como ações coletivas se estruturam na formação dos mercados.

A fidelidade dos produtores com compradores é uma das questões centrais para a concorrência entre empresas no mercado de leite. Segundo o dirigente de um dos sistemas de cooperativas de leite, "é fundamental, determinante, ter controle da matéria prima”. As cooperativas precisam de estabilidade, da garantia de que os produtores vão entregar a quantidade de leite compromissada com a indústria. Em todo o mercado de leite das últimas décadas, a principal estratégia utilizada pelas empresas compradoras para atuar em um mercado altamente instável e fortemente competitivo é o estabelecimento de relacionamentos duradouros entre produtores e compradores (Nassar et alii, 2002). Estabilizar as relações entre indústria e fornecedores é, segundo Fligstein (2001), o principal desafio das firmas. No mercado de leite, a constante guerra de preços é um fator de desestabilização das relações entre os agentes, e por isso as empresas buscam formar coalizões que garantam condições estáveis de acesso à matéria-prima.

Essa relação pode ser analisada à luz dos incentivos econômicos que as empresas oferecem aos produtores, sendo esse o tipo de incentivo que as empresas e cooperativas tradicionais normalmente utilizam. Ademais, nas três cooperativas da agricultura familiar, além dos incentivos econômicos, são mobilizados também incentivos de outra ordem, que passaremos a descrever a seguir.

\section{Incentivos econômicos}

A principal estratégia utilizada pelas empresas tradicionais para manter a fidelidade dos produtores é o uso de incentivos econômicos, principalmente por meio de políticas de bonificação. Consiste em um sistema de diferenciação de preço que visa estimular o aumento da pro- dução, da produtividade, e a melhoria da qualidade do leite. Dependendo da quantidade e da regularidade da produção, da utilização de equipamentos modernos na produção e armazenamento do leite, da realização periódica de testes e vacinações, os preços podem variar em até 70\% entre produtores de uma mesma região (Testa et alii, 2003, p. 37).

Com forte crítica à discriminação dos produtores menos capitalizados, a formação das cooperativas de agricultores familiares foi uma alternativa explícita à política de bonificação. No início, todas as cooperativas passaram a adotar um preço único, provocando assim grande elevação do preço recebido pelos pequenos produtores. Porém, as cooperativas vêm sofrendo um agressivo ataque das empresas que oferecem preços mais altos para os maiores e melhores produtores. Isso fez com que as cooperativas começassem também a adotar uma política de diferenciação de preços, ainda que mais branda. O combate à bonificação representa, para as cooperativas, uma forte contradição. Ao mesmo tempo em que foi tema importante da luta política dos sindicatos e um dos fortes motivadores para a criação das próprias cooperativas, sua eliminação reduz a capacidade que as cooperativas têm de manter a relação com os maiores produtores, melhorar a qualidade e aumentar a estabilidade da oferta. Considerando esse contexto político, para as cooperativas esse é um incentivo pouco eficaz.

Outro tipo de incentivo econômico utilizado para garantir a fidelidade dos produtores é a oferta de assistência técnica e financiamento para os produtores de leite. Pesquisa realizada pela Cocel mostra que mais de $80 \%$ dos produtores concentram-se nas faixas de produção de 5 a 75 litros de leite por dia. A cooperativa considera que o volume ideal seria uma produção mínima de 100 litros diários, uma faixa em que estão apenas 5\% dos produtores. Dos 1.164 produtores de leite, 345 possuíam ordenhadeiras, dos quais apenas 34 possuíam equipamentos de resfriamento a granel; 538 resfriamento de imersão; 550 empregando congeladores; e 34 utilizando geladeiras. Os dados mostram que, apesar de todos utilizarem algum tipo de resfriamento para a conservação do leite, as condições de armazenamento são ainda precárias para a maioria dos produtores.

Outra importante restrição é a carência de assistência técnica. Um quarto dos produtores nunca recebeu nenhum tipo de assistência técnica; pouco mais de um terço recebe visitas de técnicos às propriedades uma ou duas vezes por ano; e apenas $8 \%$ dos produtores recebem visitas mensais. A inseminação artificial é uma prática mais corrente entre os produtores, pois quase metade a utiliza 
pelo menos em parte dos animais. Porém, para um terço dos produtores e aproximadamente metade dos animais, essa é uma técnica que nunca foi utilizada. Segundo os dirigentes das cooperativas, as empresas que compram leite na região oferecem assistência técnica apenas para os produtores que entregam acima de mil litros por mês. A maioria dos pequenos produtores, portanto, não tem acesso a esse importante serviço. Nesse sentido, é evidente por que os produtores vendem sua produção para as cooperativas, mesmo recebendo preços menores devido ao acesso à assistência técnica, inseminação, capacitação e financiamento.

Para viabilizar o financiamento, as cooperativas de produtores de leite têm uma forte relação com cooperativas de crédito. Assim como ressalta Granovetter (2001), as ligações estreitas entre agentes financeiros, produtores e comerciantes são determinantes nos processos de inovação. A necessidade de implantação da coleta e transporte de leite resfriado a granel obrigou os produtores a instalar resfriadores de leite nas propriedades. Muitas empresas passaram a financiar os produtores para a aquisição do equipamento, constituindo assim uma forma de dependência entre produtores e empresas. As cooperativas de crédito do Sistema Cresol oferecem serviços financeiros para a produção de leite, especialmente o financiamento para a aquisição dos equipamentos, de animais, prestando ainda serviço de pagamento dos produtores. Segundo técnicos da Cresol-Baser, no último ano, 60 a $70 \%$ da carteira das cooperativas de crédito da região foram destinados a financiamentos da produção de leite.

Os incentivos econômicos são muito criticados por lideranças locais e mesmo pelos próprios dirigentes das cooperativas como uma forma tradicional de exclusão. É uma contradição permanente entre a racionalidade econômica e os objetivos sociais das cooperativas. Porém, mais do que engessar as organizações em infindáveis discussões e conflitos internos, essa contradição força as organizações a buscarem inovações que possibilitem a combinação de eficiência econômica e inserção social (Magalhães, 2005). A solução desse conflito foi, em parte, viabilizada pela importância menor que os incentivos econômicos têm para as cooperativas em comparação com as grandes empresas, graças aos incentivos não econômicos desenvolvidos no processo histórico a partir do qual as cooperativas foram criadas.

\section{Incentivos não econômicos}

A fidelidade dos produtores é garantida, sobretudo, por incentivos simbólicos mobilizados pelas cooperativas e que se baseiam na identidade que os produtores familiares têm com os vínculos comunitários e na identidade política construída pelos sindicatos da agricultura familiar.

Para compreender como esses incentivos influenciam o comportamento dos indivíduos, é necessário ter em mente quais são os objetivos da ação nas relações sociais subjacentes às transações econômicas. Para Fligstein (1999), o objetivo básico da ação é obter a cooperação dos outros atores, sendo esse o resultado de identidades coletivas, mais do que de interesses individuais. A habilidade para obter cooperação pode ser vista genericamente como uma habilidade social cuja base cognitiva vem da psicologia social, em especial da corrente do interacionismo simbólico (Mead, 1934), segundo a qual os indivíduos agem conforme suas crenças e valores, sendo esses os princípios elementares de sua identidade. Os valores e as crenças organizam os objetivos e os meios sociais que os indivíduos utilizam para atingi-los.

As relações entre as cooperativas e os produtores foram fortalecidas por meio de laços comunitários, por uma simples, porém determinante, mudança no sistema de transporte do leite. O controle do transporte é uma importante estratégia de concorrência no mercado de leite. Os freteiros ou transportadores são os agentes que fazem a coleta de leite nas propriedades e atuam como intermediários na relação entre indústria e produtores. A relação entre produtores e freteiros vai muito além do que aparenta ser apenas uma prestação de serviços. O contato freqüente, quase diário, e de longo período entre os produtores e os freteiros cria relações de proximidade e laços de confiança (Abramovay, 2000, p. 301) que são determinantes na concorrência entre as empresas. Às relações de mercado são sobrepostos vínculos políticos, de vizinhança, de parentesco, de reciprocidade, etc.

Mesmo recebendo preços mais baixos, alguns produtores mantêm a fidelidade com indústrias devido aos laços de compromisso com os freteiros. Como relata um produtor familiar de leite em Francisco Beltrão, no Paraná: "Muitas famílias não saem da empresa porque o freteiro é bom, mesmo que receba 10 centavos a menos". Diversos outros serviços necessários à atividade de produção ou às variadas necessidades das famílias são atendidos pelos freteiros. Essa relação de dependência que o sistema tradicional de transporte impõe aos produtores reduz a liberdade de escolha no mercado. Nessas relações se estabelecem regras de troca que definem quem pode transacionar com quem e as condições em que as transações são realizadas.

A substituição dos intermediários externos por intermediários da própria organização, normalmente pessoas escolhidas nas comunidades, significou uma importante 
mudança nos direitos de propriedade, estabelecendo-se novas relações de poder e hierarquia. As linhas passaram a ser coordenadas pelos próprios produtores, com o apoio de lideranças locais e representantes da cooperativa, fazendo com que os laços comunitários passassem a ter um peso primordial nas relações entre os produtores e as organizações.

Incentivos simbólicos também se expressam por meio da identidade dos produtores com os sindicatos da agricultura familiar, o que contribui expressivamente para gerar uma forte coesão social entre os associados. A maioria das cooperativas foi formada por lideranças dos sindicatos que passaram a exercer cargos de direção nas duas organizações. Essa proximidade permite uma importante combinação entre racionalidade econômica na gestão das organizações e uma coesão social que fortalece os vínculos.

No entanto, a relação com os sindicatos não é isenta de tensões. Em muitos municípios, as cooperativas têm grandes dificuldades relacionais com esses organismos. As cooperativas buscam construir sua autonomia e uma racionalidade baseada na viabilidade econômica e na relação com os mercados, enquanto os sindicatos se orientam e tentam orientar as cooperativas segundo seus objetivos políticos. Reivindicam inclusive maior contribuição financeira das cooperativas para as lutas e mobilizações organizadas pelos sindicatos. As cooperativas não discordam da importância que as lutas sindicais têm para a sua própria viabilidade econômica, mas defendem que a sua contribuição deve ser orientada por resultados concretos.

Um segundo ponto de tensão refere-se à visão sobre os mercados. Os sindicatos possuem visões de mundo eminentemente avessas às regras dos mercados, enquanto as novas concepções de controle formadas pelas cooperativas de leite foram resultado de mudanças culturais, sobretudo de um processo de racionalização econômica constantemente questionada pelas organizações sindicais. Dessa maneira, a formação desse campo estruturado pelas organizações da agricultura familiar pode ser caracterizada por um sistema de oposições fundamentais: a combinação conflituosa de racionalidade econômica e cultura política. Processo semelhante a esse foi descrito em um trabalho sobre as cooperativas de crédito no sertão da Bahia, onde a adesão à racionalidade econômica não levou necessariamente ao abandono dos valores que serviram de fundamento à construção histórica da comunidade e à sua coesão (Magalhães, 2005, p. 136). Pelo contrário, a eficiência econômica e o resultado social da ação de organizações econômicas e movimentos sociais se explicam, justamente, pela associação existente entre a racionalida- de econômica e a cultura política dos movimentos. Essa combinação quase inusitada é a característica central que define a forma singular como as cooperativas construíram a sua capacidade de competir nos mercados.

\section{CONCLUSÕES}

Os estudos tradicionais que se valem apenas de preços e mercados não são capazes de compreender como os resultados históricos de construções sociais e a habilidade de atores para a mobilização de diferentes formas de capital alteram as estruturas de um mercado e determinam as novas posições que os atores passam a ocupar. Nesse estudo sobre o papel das cooperativas no mercado de leite, apesar das diferenças de estilo e de pressupostos, as abordagens da Sociologia Econômica e da Economia Institucional destacam, com importante complementaridade, as formas concretas de interação social nos mercados. Ao contrário das abordagens neoclássicas, que tratam os mercados como mecanismos de formação de preços que podem ser conhecidos de maneira dedutiva, em uma análise institucional e sociológica dos mercados as propriedades são muito mais particularizadas, conhecidas por meio de métodos fundamentalmente indutivos e baseadas na reconstrução de processos históricos (Abramovay, 2004).

A Economia Institucional possibilita identificar a existência de altos custos de transação na relação entre produtores de leite e indústrias de processamento fazendo com que o controle do mercado por parte das grandes empresas seja parcial. Ao lado dessa conclusão, a Sociologia Econômica mostra que em um mercado caracterizado pela presença de um grande número de pequenas, médias e grandes empresas, interagindo num processo de grande concorrência, onde as empresas líderes não estão definidas, as habilidades sociais são determinantes para que certas organizações ocupem um espaço de destaque.

A falta de capital econômico é compensada, nas cooperativas, por fortes e densos capitais, especialmente simbólico, social e tecnológico. As organizações da agricultura familiar desse território conseguem mobilizar essas diferentes formas de capital, constituído ao longo de décadas de organização social iniciada pelas Comunidades Eclesiais de Base e levada adiante pela ação política, pedagógica e organizacional patrocinada pelos sindicatos de trabalhadores rurais e pelas ONGs.

Uma visão histórica dos movimentos sociais da agricultura familiar revela uma mudança estratégica substancial nas suas visões sobre os mercados: o esforço de formação de projetos políticos e sociais novos, cujos objetivos 
centrais são ampliar a participação da agricultura familiar nos mercados ao lado da ação tradicional que visa buscar maior acesso aos recursos públicos. Essas novas habilidades dos movimentos sociais da agricultura familiar se materializam na forma de estruturas de governança formadas pelas cooperativas com dois focos fundamentais. O primeiro torna-se compreensível pela abordagem da Economia Institucional e evidencia a formação de sistemas de governança eficientes no campo das relações sociais e econômicas entre os produtores e as organizações. O segundo emerge à luz da Sociologia Econômica, evidenciando a formação de uma forte identidade comunitária e política entre as organizações da agricultura familiar e entre os agricultores familiares. Ou seja, as estratégias construídas pelas organizações para garantir a relação estável com os produtores não se restringem ao campo econômico. A combinação de princípios ideológicos e capital simbólico que garanta a coesão social de um grande número de lideranças comunitárias, sindicais e de outras organizações sociais aliada a uma capacidade de gestão econômica racional na relação com o mercado e na administração das cooperativas forma um tipo de controle que tem se mostrado eficiente e capaz de concorrer com grandes empresas multinacionais do setor. A criação das cooperativas modificou tradicionais sistemas de hierarquia e dominação social, como, por exemplo, a relação entre freteiros e produtores, e a relação de dependência financeira entre agricultores e indústrias de leite, formando novos laços entre os agricultores familiares e as organizações. A capacidade de organização, aliada à capacidade de formar coalizões com algumas indústrias regionais de médio porte, faz com que as cooperativas da agricultura familiar ocupem parcela importante e crescente do mercado.

As cooperativas de leite formaram também estruturas de governança com o objetivo de estreitar suas relações com os governos e ampliar o acesso às políticas públicas. Os principais projetos financiados com recursos públicos, como capacitação, assistência técnica, infra-estrutura e crédito, são fruto da negociação direta entre o Fórum Sul do Leite e o Sistema Cresol de cooperativas de crédito e instâncias federais do governo, especialmente o Ministério do Desenvolvimento Agrário, o Banco do Brasil e o BNDES. As negociações entre as cooperativas de leite e de crédito com o governo são articuladas de forma mais ou menos planejada com as lutas sindicais. A organização sindical exerce o papel político amplo e relativamente difuso de promover maior visibilidade da agricultura familiar na sociedade e exercer pressão política sobre o governo.
As cooperativas de leite da agricultura familiar são organizações setoriais que têm fortíssima repercussão sobre o conjunto do território, já que elas se voltam a coordenar um conjunto de atividades nas quais se envolvem milhares de atores econômicos locais. Apesar do papel econômico muito bem determinado, as cooperativas exercem também importante influência sobre outros campos de relações sociais dos territórios, mostrando que existe um forte entrelaçamento entre campos econômicos, políticos, sociais e culturais.

Por fim, esta pesquisa sobre o mercado de leite contribui para o debate sobre um importante aspecto conceitual e, ao mesmo tempo, operacional das políticas de desenvolvimento rural. O novo enfoque traz ganhos significativos em comparação com a visão exclusivamente setorial das políticas de desenvolvimento. A análise desse mercado mostra que os enfoques setoriais e territoriais, tanto do ponto de vista teórico quanto da operacionalização de políticas, poderiam e deveriam ser complementares. Além disso, do ponto de vista teórico, a análise das interações sociais, base do próprio conceito de território e de mercado, também deveria incorporar a análise dos interesses econômicos e políticos dos atores, suas visões de mundo e formas de racionalidade, bases sobre as quais se estabelecem os conflitos e as coalizões entre os atores sociais e a partir das quais podem ser melhor compreendidas. Ou seja, uma compreensão mais nítida dos mercados depende da observação das condições específicas da sua formação histórica em cada território.

\section{AGRADECIMENTO}

Esse artigo foi elaborado a partir de pesquisa realizada no âmbito do programa Movimientos Sociales, Gobernanza Ambiental y Desahollo Territorial Rural, do Rimisp - Centro Latinoamericano para el Desarrollo Rural, realizada no Brasil pela Fipe (Fundação Instituto de Pesquisas Econômicas), com o projeto As Forças Sociais dos Novos Territórios - O caso da Mesorregião Grande Fronteira Mercosul. Agradeço ao prof. Ricardo Abramovay e a Mônica Schroder pelo trabalho conjunto e pelos importantes comentários sobre o artigo.

\section{REFERÊNCIAS}

ABRAMOVAY, R. O capital social dos territórios: repensando o desenvolvimento rural. São Paulo: Economia Aplicada, v. 4, n. 2, p. 379-397, 2000.

ABRAMOVAY, R. Entre Deus e o Diabo - mercados e interação humana nas ciências sociais. Tempo Social - Revista de Sociologia da USP, 2004. 
BIALOSKORSKI NETO, S. A nova geração de cooperativas e a coordenação dos sistemas agroindustriais. II Workshop Brasileiro de Gestão de Sistemas Agroindustriais. Ribeirão Preto: FEA/USP, 1999.

BIALOSKORSKI NETO, S. Estratégias e cooperativas agropecuárias: um ensaio analítico. Seminário de Política Econômica em Cooperativismo e Agronegócios. Viçosa: UFV, 2002.

BOURDIEU, P. As estruturas sociais da economia. In: Politica E Sociedade, n. $6,2005$.

CARVALHO, V. R. F. Indústria de laticínios no Rio Grande do Sul: um panorama após o movimento de fusões e aquisições. $1^{\circ}$ Encontro de Economia Gaúcha. Porto Alegre: FEE, 2005.

FLIGSTEIN, N. Social Skills and the Theory of Fields. Berkeley: University of California, 1999.

FLIGSTEIN, N. The Architecture of Markets - An Economic Sociology of Twenty-First-Century Capitalist Societies. Princeton and Oxford: Princeton University Press, 2001.

GARCIA-PARPET, M.-F. A construção social de um mercado perfeito: o caso de Fontaines-en-Sologne. In: Estado, Sociedade e Agricultura. n. 20, CPDA, 2003

GEERTZ, C. Local Knowledge. New York: Basic Books, 1983.

GRANOVETTER, M. Economic action and social structure: the problem of embededdness. In: American Journal of Sociology, v. 91, n. 3, p. 481$510,1985$.

GRANOVETTER, M. A theoretical agenda for economic sociology. New York: Department of Sociology / Stanford: Stanford University, 2001.

JANK, M. S.; GALAN, V. B. Itambé: o desafio das cooperativas no novo cenário do leite brasileiro. São Paulo: Pensa, Estudos de Caso, 1997.

KARLSON, D. Organizational models in U.S. agricultural cooperatives. SLU, Institutionen för Ekonomi: Företagsekonomi, 2005.
MAGALHÃES, R. S. Economia, natureza e cultura. Dissertação de mestrado defendida no Programa de Ciência Ambiental, São Paulo: USP, 2005.

MEAD, G. H. Mind, Self, and Society. Chicago: University of Chicago Press, 1934.

NASSAR, A. M.; NOGUEIRA, A. C. L.; FARINA, T. Pool Leite ABC: inovando na comercialização de leite. Seminários Pensa de Agronegócios: Redes e Estratégias Compartilhadas. São Paulo: PENSA, FIA, 2002.

NEVES, M. F. et alii. Mapeamento e quantificação da cadeia do leite. Ribeirão Preto: PENSA/FEA-RP/USP, 2005.

NORTH, Douglas. Institutions, institutional change and economic performance. Cambridge: Cambridge University Press, 1990.

PILATI, Nilson. Avaliação dos produtos e serviços da Coorlac na perspectiva do canal de distribuição. Monografia apresentada ao Programa de Pós-Graduação em Administração, Porto Alegre: Universidade Federal do Rio Grande do Sul, 2004.

SWEDBERG, Richard. Principles of Economic Sociology. Princeton: Princeton University Press, 2003

TESTA, V. M.; MELlO, M. A.; FERRARI, D. L.; SILVESTRO, M. L.; DORIGON, C. A escolha da trajetória da produção de leite como estratégia de desenvolvimento do oeste catarinense. Florianópolis: Epagri, 2003.

WHITE, H. C. Where do markets come from? In: American Journal of Sociology. v. 87, n. 3, p. 514-547, 1981.

WILLIAMSON, O. Transaction cost economics. In: SCHMALENSEE, R.; WILLIG, R. D. Handbook of Industrial Organization, v. I, Elsevier Science Publ., 1989.

ZYLBERSZTAJN, D. Estruturas de governança e coordenação do agribusiness: uma aplicação da Nova Economia das Instituições. Tese de Livre Docência. Departamento de Administração, São Paulo: Universidade de São Paulo, 1995.

Artigo recebido em 17.10.2005. Aprovado em 24.01.2007.

\author{
Reginaldo Sales Magalhães \\ Doutorando em Ciência Ambiental pelo Procam - USP. Especialista em Sociedade Civil da \\ International Finance Corporation e Diretor da Plural Consultoria e Pesquisas. Membro do \\ Grupo de Pesquisas Instituições do Desenvolvimento Territorial da Faculdade de Economia \\ e Administração da USP. \\ Interesses de pesquisa na área de sociologia econômica. \\ E-mail: regi.magalhaes@uol.com.br. \\ Endereço: Rua Dr. Nogueira Martins, 400, apt. 104, São Paulo - SP, 04143-020.
}

